\title{
The Effect of Backrest Roller on Warp Tension in Modern Loom
}

\author{
Toufique Ahmed, (M.Sc.) \\ Department of Textile Engineering, National Institute of Textile of \\ Engineering \& Research, Dhaka, Bangladesh \\ Kazi Sowrov, (M.Sc.) \\ Department of Fabric Engineering \\ Shaikh Md. Mominul Alam, (PhD) \\ Department of Textile Machinery Design and Maintenance, Bangladesh \\ University of Textiles, Bangladesh
}

doi: 10.19044/esj.2017.v13n9p127 URL:http://dx.doi.org/10.19044/esj.2017.v13n9p127

\begin{abstract}
The Backrest roller is one of the key parts of the weaving machine. In this study, the effect of the various position of backrest and dropper has been assessed. The tension is measured by using the integrated tension measuring device of the loom. The tension can be found on the display board. The effect of backrest position can be described in two different ways viz. keeping constant dropper position (distance between dropper line and backrest roller) and keeping constant dropper depth (distance between held frame and dropper line). If dropper position (distance between backrest roller to dropper line) is kept constant then the backward movement of backrest roller will entail low tension. The reason behind this is, the dropper weight will be moved toward the backrest roller and will lose its influence on warp tension. But if dropper depth is kept constant (i,e dropper line is kept intact) then the backward movement of backrest will require more tension as the influence of dropper will more on warp length. On the other hand, when backrest height is lowered then, the downward movement of backrest roller will need low tension and upward movement of backrest roller will need more tension. As the warp length and lap angle increases with the backrest height. In this paper, the whole phenomenon is explained with illustration.
\end{abstract}

Keywords: Backrest position; backrest height; dropper position; dropper depth, warp tension 


\section{Introduction}

Weaving is one of the most important fabric manufacturing processes. For producing good quality fabric proper warp tension is a vital need. High tension may cause high warp breakage and low tension can cause different fabric faults. For ensuring proper warp tension electronic warp control (EWC) is used in the modern loom. But changing of different loom setting points can play an important role in determining proper warp tension which may be an important tool for eliminating starting mark, weaving damage, frequent false stoppage etc.

The backrest is one of the most crucial parts of loom setting. It affects the fabric properties and quality. Fabric appearances, dimensional stability, starting mark, tensile strength etc are directly related with backrest roller position. H. Tahakori Shad et. al. (H. Tahakori Shad, 2013) found that the position of backrest roller has significant effect on breaking strength, elongation at break; tear resistance, abrasion resistance, air and water permeability etc. on grey fabric along the warp but it has no significant influence on the breaking strength in the weft direction, weft yarn density, abrasion resistance, and fabric weight. The tension of the warp is determined by the vertical backrest roller position, horizontal backrest roller position, warp beam diameter during the weaving process, $M$. sheikhzadeh et. al. (M Sheikhzadeh, 2007) have studied it. There is a relation of backrest roller and shed geometry during weaving. Turhan et. al. (Turhan Y, 2007) presented experimental, computational intelligence based and statistical investigations of warp tensions in different back-rest oscillations. To have different backrest oscillations, springs with different stiffness were used. For each spring, fabrics with various weft densities were woven, and the warp tensions were measured and saved during the weaving process. Kloppels M et. al. (Kloppels M, 2002) reported that the variations in warp yarn tension during the weaving process become smaller by the backrest roller's swinging motion. At a high speed of the weaving machine, it could be possible to obtain a suitable relationship between movements of the backrest roller and warp yarn tension. The empirical data were analyzed by using linear multiple and quadratic multiple regression, and an artificial neural network model has been developed. Osthus et. al. (Osthus T, 1995) reported that the warp ends tensions are influenced by changing the height of the backrest roller. However in modern looms tension is mainly determined by the warp let off and take up motions. One of the main purposes of warp let-off motion is to keep the tension constant from full beam to empty beam. Warp tension variations during weaving cause irregularity in weft density, physical properties and dyeing of woven fabrics. Weindorfer $\mathrm{H}$ et. al. (Weindorfer $\mathrm{H}, 1991$ ) investigated that there is a relation of backrest roller and shed geometry during weaving. By lifting the backrest the elongation of warp yarn in lower shed increases as a result warp tension also 
increases in the lower shed. On the other hand in upper shed elongation of warp decreases and so the tension. Previously at the decade of 1950 Hunt mechanical let off was installed on British and American weaving machines reported by Deroche P and Traynard O. (P, 1989). Later SulzerRuti introduced survo motor for let-off mechanism. The motor speed was controlled by the position of backrest roller. Now a days for measuring the warp tension in electronic warp let-off mechanisms-backrest roller is used as the measuring element (Marks R, 1976). Hence it is preferred to keep average warp tension constant and if the mean warp tension during every cycle of loom was the same throughout a warp, let-off would be considered perfect from this point of view (Foster R.,1961). Practically, the adjustment of equal tension at all threads is a challenging task in case of long floated like $3 / 3$ twill, matt or rib. In these cases, the yarn of specific long float get loose and make the dropper to be fallen on the electrode which will cause frequent false stoppage of the machine.

\section{Materials and Methods}

For this work, Leonardo rapier looms are selected. The looms have a display board which displays the required tension of the warp yarn. The backrest roller settings of the looms are changed and the tension variation for this changed is observed. At first, the backrest position of the loom has been back-warded and the change in tension is observed in comparison to the previous tension. By this method more than 5 readings are taken. Subsequently, other settings like back rest height (up and down), dropper position (forward and backward) etc. are changed and for each change the change in warp tension is measured. for each case, more than 5 data has been taken.

\section{Details of the looms}

The looms were manufactured by Promatech and branded as Leonardo HI drive and Leonardo silver looms. The origin of the loom is Italy. Leonardo is an automatic rapier loom. Here shedding mechanism is electronic dobby system, picking is flexible double rapier system and beating is modern cam beat up system. In the case of Hi drive version, automatic rpm change is possible without changing driver and driven pulley. In Fig. 1 and Fig. 2 the overall view and partial view has been illlustrated. 

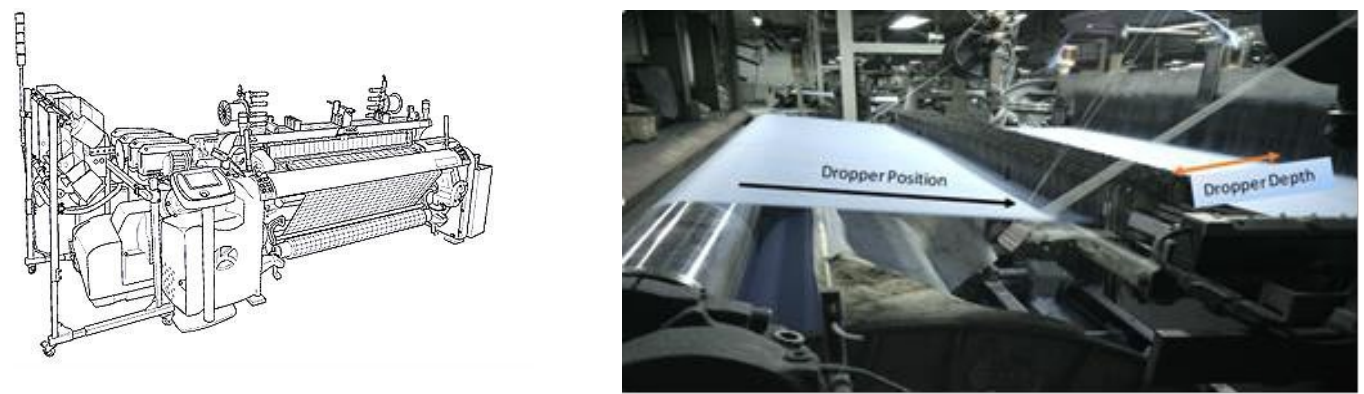

Fig.9: Schematic diagram of the Loom (Leonardo)

Fig.8: Backside of the Loom

\section{Details of the fabric}

For this task warp yarn of $40 / 1 \mathrm{Ne}$ has been selected. The fabric structure was plain (1/1). Fabric construction is as follow:

Total ends: 7670

$$
\frac{40 \times 40}{110 \times 80} \times 70^{\prime \prime}
$$

\section{Various backrest setting}

The backrest setting may be changed by:

1. Changing of Backrest Roller Position (Horizontal displacement of Backrest roller): the tension for lowest backrest roller position has been recorded and then the backrest has been moved to back and the tension has been recorded.

2. Changing of backrest Height (vertical displacement of Backrest roller): The required tension is recorded at a specific backrest height and then the backrest has been lowered or upped and for each case the tension is recorded.

\section{Measurement of warp tension}

In this loom, warp tension can be controlled by electronic warp control. For ensuring proper tension synchronized take up motor and let off motor are provided. Both motors are survo type motor. To measure tension here a tension measuring device is attached to the backrest roller. The electronic drive controls the let-off according to the signals picked up by a load cell that reads the flexion of this; this signal depends on the force that the warp ends transmit to the backrest roller and thus the warp tension. The value of the signal and the warp tension in $\mathrm{cN}$ are displayed on the display board. The position of the load cell is illustrated in Fig. 3 . 


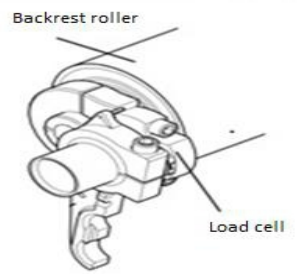

Fig. 10: Load cell in backrest roller for measuring tension

\section{Results and Discussions}

\section{Effect of Changing Backrest Roller}

Backrest position creates very interesting and peculiar effect on warp tension, it is a surprising thing that only backrest position does not create any impact on warp tension but jointly with dropper position from backrest it effects the warp tension at a great scale. The effect changing the position of backrest roller can be classified in two ways as follow:

1. Constant dropper position

2. Constant dropper depth

Table 1: Effect of backrest position (constant dropper position)

\begin{tabular}{ccccc}
\hline $\begin{array}{c}\text { Backrest position } \\
(\mathrm{cm})\end{array}$ & $\begin{array}{c}\text { Dropper height } \\
(\mathrm{cm})\end{array}$ & $\begin{array}{c}\text { Dropper Position } \\
(\mathrm{cm})\end{array}$ & $\begin{array}{c}\text { Dropper height } \\
(\mathrm{cm})\end{array}$ & $\begin{array}{c}\text { Tension } \\
\text { /End }(\mathrm{cN})\end{array}$ \\
\hline 14 & 0 & 35 & 5.5 & 34 \\
17 & 0 & 35 & 5.5 & 33 \\
18 & 0 & 35 & 5.5 & 31 \\
19 & 0 & 35 & 5.5 & 28 \\
20 & 0 & 35 & 5.5 & 27 \\
\hline
\end{tabular}

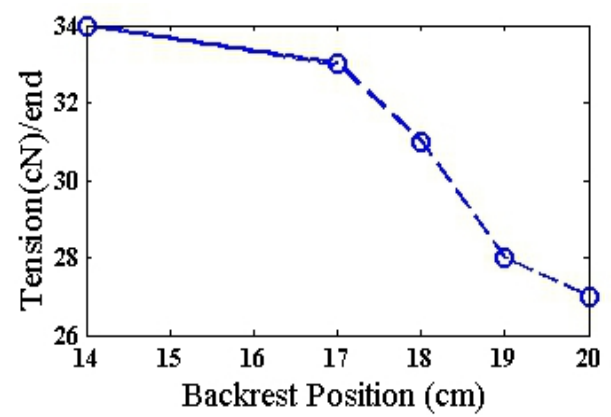

Fig. 11: Tension decreases while backrest roller retreating 


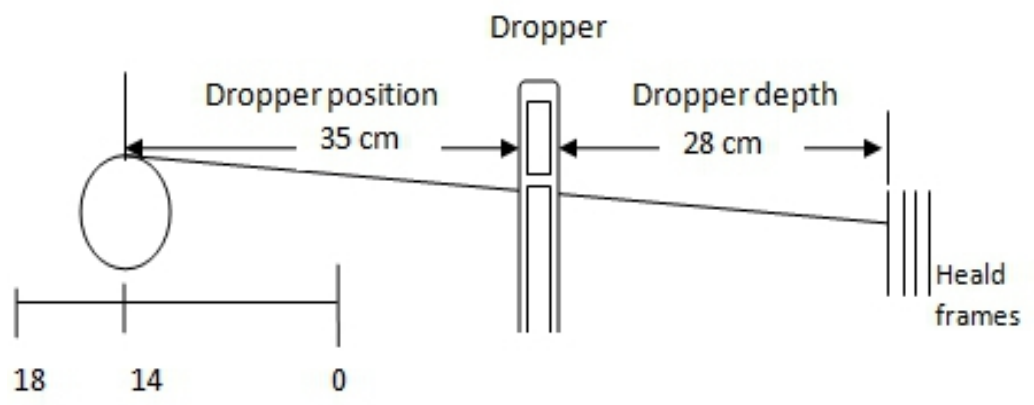

Fig. 5-a: Dropper line is closer to the heald frame when backrest position is 14. (more tension is required)

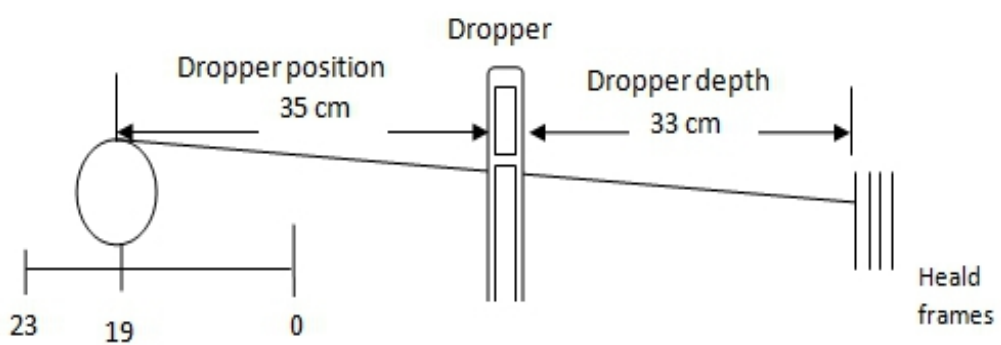

Fig. 5-b: Dropper depth increased to $33 \mathrm{~cm}$ from $28 \mathrm{~cm}$ when backrest position is 19 (less tension is required)

The effect of Backrest position is influenced by the position of dropper line. When the dropper line keeps its position constant (i,e both the backrest and dropper line is moved) then the backward position of the backrest roller will reduce the required tension.(as shown in Table $1 \&$ Fig. 4). The reason behind this is, once the backrest is moved backward keeping the dropper position constant then the dropper depth increases (Fig. 5-a and 5-b) which ultimately bring the dropper line near to the backrest in comparison with the dropper depth hence the impact of dropper weight will little as a result low tension will be required.

\section{Constant dropper depth}

Constant dropper depth means the distance between dropper line and heald frame will be constant. In another word the dropper line will be intact. To determine the effect of this group some observations are made: 
Table 2: Effect of backrest position (constant dropper depth)

\begin{tabular}{cccc}
\hline $\begin{array}{c}\text { Backrest Height } \\
(\mathrm{cm})\end{array}$ & $\begin{array}{c}\text { Dropper position } \\
(\mathrm{cm})\end{array}$ & $\begin{array}{c}\text { Dropper Height } \\
(\mathrm{cm})\end{array}$ & $\begin{array}{c}\text { Tension /end } \\
(\mathrm{cN})\end{array}$ \\
\hline 0 & 30 & 6 & 26 \\
0 & 32 & 6 & 30 \\
0 & 35 & 6 & 31 \\
0 & 36 & 6 & 32 \\
0 & 37 & 6 & 33 \\
0 & 38 & 6 & 34 \\
\hline
\end{tabular}

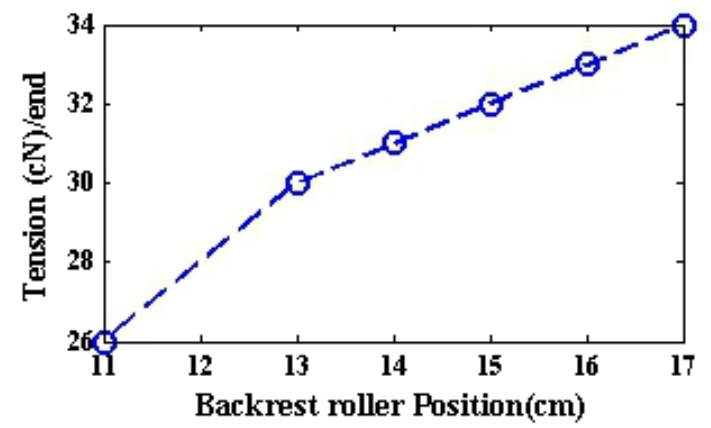

Fig.6: Tension increases while the backrest roller retreating

It is seen that the changing of backrest roller keeping dropper line intact $i, e$ moving the backrest roller keeping the dropper depth constant will require more tension as shown in Fig. 6. The reason is illustrated as follow:

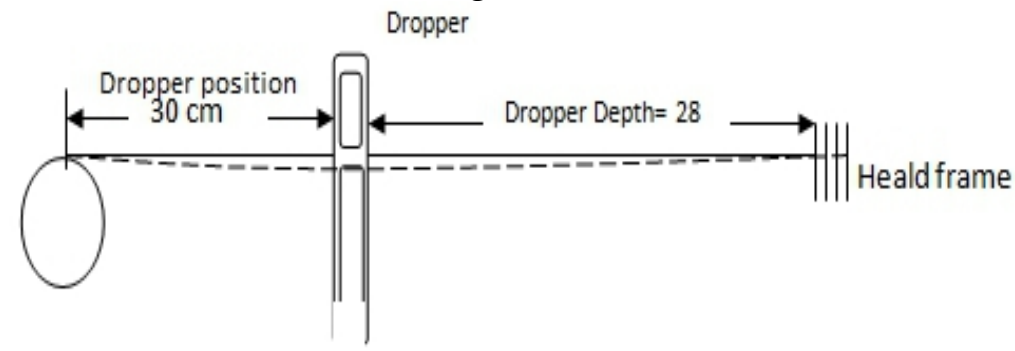

Fig. 7-a: various distances when dropper position 30cm (keeping dropper line intact)

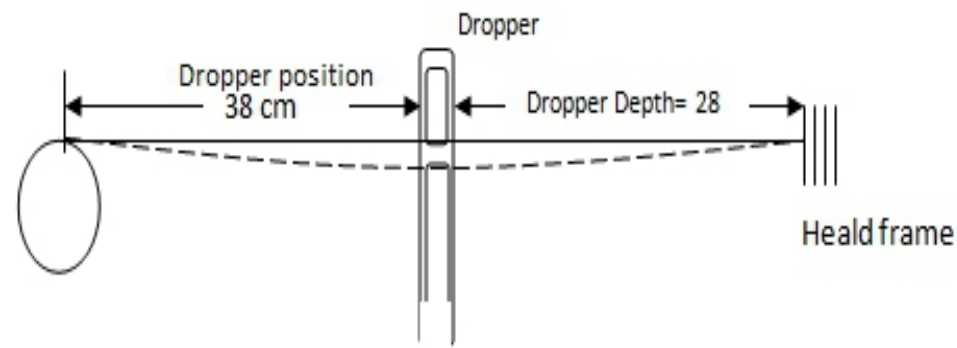

Fig. 7-b: Retreating backrest roller (keeping dropper line intact). 
In Fig. 7-a and 7-b it is illustrated that the distance between backrest roller and dropper line is kept constant but the distance between dropper line and heald frame changes. In this case when the backrest roller is moved backward keeping the dropper depth unaffected then the dropper position increases (Fig. 7-a \& Fig. 7-b). So in the case of lower backrest position (like in Fig. 7-a), the impact of dropper will be lower due to the sagging of warp. But in the case of higher backrest position (like in Fig. 7-b), the influence of dropper will be more so as the sagging of warp. In this scenario, it necessitates more tension to maintain the proper level of the shed.

\section{Effect of changing backrest height}

For analyzing the effect of backrest position some data have been collected from different backrest height but same in backrest position, dropper position, dropper height etc. The data is summarized as follow: Here (-)ve sign indicates the downward position and (+) ve sign indicates the upward position of the backrest.

Table 3: Effect of backrest height on warp tension

\begin{tabular}{ccccc}
\hline $\begin{array}{c}\text { Backrest position } \\
(\mathrm{cm})\end{array}$ & $\begin{array}{c}\text { Backrest } \\
\text { Height } \\
(\mathrm{cm})\end{array}$ & $\begin{array}{c}\text { Dropper position } \\
(\mathrm{cm})\end{array}$ & $\begin{array}{c}\text { Dropper Height } \\
(\mathrm{cm})\end{array}$ & $\begin{array}{c}\text { Tension/end } \\
(\mathrm{cN})\end{array}$ \\
\hline 18 & -2 & 36 & 5 & 30 \\
18 & -3 & 36 & 5 & 26 \\
18 & 0 & 36 & 5 & 31 \\
18 & 1 & 36 & 5 & 33 \\
18 & 2 & 36 & 5 & 34 \\
\hline
\end{tabular}

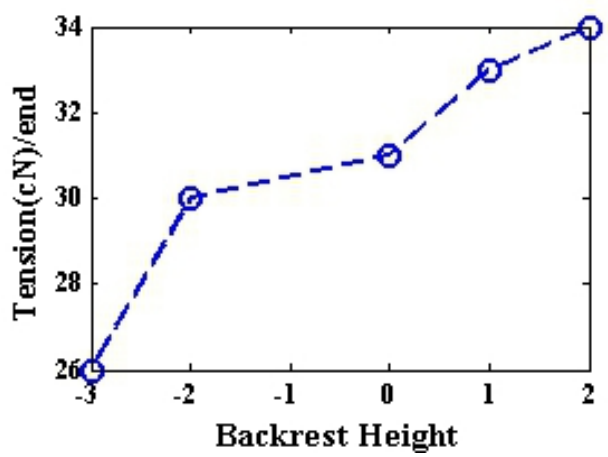

Fig. 8 Tension increases according to the backrest height

From the Table 3 it is seen that downward position of backrest height will require low tension but the upward position of backrest roller will require high tension.(Shown in Fig.: 8)

In the case of downward backrest height, the effect of drop wire weight on warp yarn will be low. So the required tension will also be low. 
But when the backrest is up warded then the effect of drop wire weight will be high so more tension will be needed to straighten the warp thread.

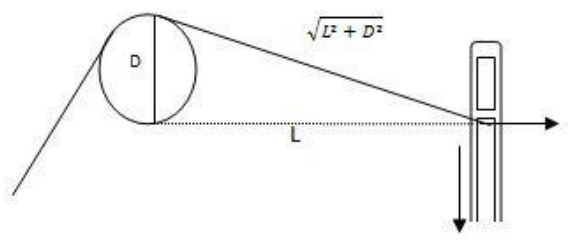

Fig. 9-a Higher backrest height

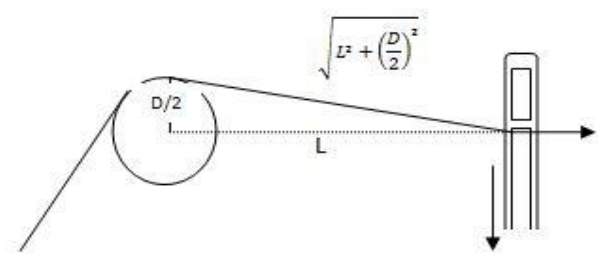

Fig. 9-b Lower backrest height

From these Figures, it is seen that the yarn length in Fig.9-a is lower than the yarn length in Fig. 9-b

Because $\sqrt{L^{2}+D^{2}}>$

$$
\sqrt{L^{2}+\left(\frac{D}{2}\right)^{2}}
$$

As the longer length has a tendency of more sagging due to weight. So the sagging in Fig. 9-a will be lower than in Fig. 9-b due to the dropper weight. So for leveling the shed, it is needed to impose more tension in case of higher backrest height.

Here all the value of Tension is constant for a single yarn except the $T_{2}$. Because $\mathrm{T}_{2}=\mathrm{T}_{1} e^{\mu \theta}$ and the value of $\theta$ depend on:-

a. Backrest height: increase backrest height will increase the value of $\theta$

b. Beam diameter: decreasing beam diameter will increase the value of $\theta$ So, due to higher backrest position and/or lower beam diameter the value of $\mathrm{T}_{2}$ will increase so that the required tension.

\section{Conclusion}

The effect of backrest roller on warp tension and fabric quality cannot be ignored in any ways. From this study, it is known that different warp tension is observed due to different settings of backrest and dropper. The reason behind this behavior is different. Although modern loom has offered accurate tension by electronic means but it is needed to readjust the tension when any settings mentioned in this paper is changed. This study let us know about the amount of tension readjustment while changing any settings related to the backrest. Improper tension is a major cause of faults like starting mark. It is often seen in the factory that the starting mark appears in the loom frequently especially after running some days. For amending the starting mark it is needed to readjust tension. If the starting 
mark is caused due to high tension then the tension should be minimized either by lowering the backrest or backward the drop wire. However, investigating the effect of tension on starting marks need higher level research using high technology like digital image processing technique.

\section{References:}

1. H. Tahakori Shad, E. H. (2013). Influence of backrest roller position on denim fabrics, Fibre \& Textiles in Eastern Europe, 21, 60-66 .

2. Kloppels M, G. T.-J. (2002). Practical Trial of the Freely Pro $\neg$ grammable Active Backrest Roller System. vol. 8(2), pp (). . Melliand-International , 115-116.

3. M Sheikhzadeh, S. A. ( 2007). Theoretical evaluation of warp tension variation during weaving process. Indian Journal of Fibre \& Textile

4. Research, 377-380 .

5. Marks R Marks R, R. A. (1976). Principles of Weaving. Man $\neg$ chester,

6. England: The Textile institute

7. Osthus T, W. B.-J. (1995). Automatic Setting of Backrest and Dropwires in

8. Mill Trial. . Melliand Textilberichte, E 207-E209.

9. P, D. (1989). L'Industries Text \& TraynardO,L'Industries Text,. L'Industries

10. Text \& TraynardO,L'Industries Text, , 47-51.

11. Turhan Y, T. S. (2007). Statistical and Computational Intelligence Tools for

12. the Analyses of Warp Tension in Different Back-rest Oscillations.

13. Information Sciences, 5237-5252.

14. Weindorfer H, W. J. (1991). The distribution of the warp end tension over the

15. warp width and how it is influenced by the weaving machine setting.

16. Mettliand Textilberichte, E260-E362.

17. Foster R. (1961). positive let off motions. Leeds: Wool Industries Research

18. Association. 